\title{
Personality profile and affective state of patients with inflammatory bowel disease
}

\author{
D A F ROBERTSON, J RAY, I DIAMOND, AND J GUY EDWARDS
}

From the Departments of Medicine II, Social Statistics and Psychiatry, Southampton University, Southampton

Summary The Eysenck Personality Inventory and Hospital Anxiety and Depression scale were administered to 80 patients undergoing medical treatment for long standing inflammatory bowel disease: 22 patients were studied before the diagnosis was established and 40 patients with diabetes mellitus served as controls. High neuroticism and introversion scores were more prevalent in the patients with inflammatory bowel disease than controls $(p<0 \cdot 05)$ and these characteristics were as prominent in patients before diagnosis as in established cases. Introversion scores increased with the duration of disease $(r=0.51)$. Depression was uncommon, occurring only in patients with active chronic disease. Patients believed there was a close link between personality, stress and disease activity. Fifty six of the patients recognised factors that initiated the disease and in 42 this was thought to be a stressful life event or a 'nervous personality'.

Physicians and surgeons often suspect that their patients with inflammatory bowel disease (IBD) are of a particular personality type. Common characteristics reported include obsessive-compulsive behaviour, neuroticism, dependency, anxiety, overconscientiousness, the inability to be appropriately aggressive or angry, and perfectionism 'A These phenomena could result from a longstandiıg chronic disease characterised by intermittent diarrhoea and abdominal pain, together with fear of ileostomy and other forms of surgery, and treatment with corticosteroids. On the other hand if present before the diagnosis was made they would support the hypothesis that IBD is more likely to occur in subjects with predisposed personalities. This paper reports a study which compared the personality profiles and affective state of patients with inflammatory bowel disease comprising patients with the established disease and patients seen on first referral to the hospital before the diagnosis was confirmed, with a control population of patients with another chronic disease, diabetes mellitus. In addition, the major sources of anxiety in patients with inflammatory bowel disease

Address for correspondence: Dr D A F Robertson, Room LD68, Level D, South Laboratory and Pathology Block, Southampton General Hospital, Tremona Road, Southampton SO9 4XY.

Accepted for publication 14 October 1988. and their perception of factors which they thought important in relapse were investigated.

\section{Methods}

PATIENTS

Eighty patients with established inflammatory bowel disease were included in the study. Of these 44 had Crohn's disease and 36 had ulcerative colitis. The mean time since diagnosis of IBD was $7 \cdot 2$ years (range 0.5-27). In 30 the disease was active and in 50 it was in remission. Mean activity index in 80 patients was 4.9. Patients were unselected and were collected from those consecutively attending as outpatients or inpatients. No patients had undergone surgery. In addition 22 consecutive new referrals to the outpatient department with a history suggestive of inflammatory bowel disease, such as rectal bleeding, diarrhoea, abdominal pain or weight loss, and later diagnosed as having IBD were studied. Crohn's disease 16; ulcerative colitis six, mean activity index = $6 \cdot 3$. The average duration of symptoms in this group was 12 weeks (range two weeks-2.5 years). The controls were 40 diabetic patients attending the diabetic clinic. Diabetic patients were chosen as controls as they have a chronic disease requiring relatively intensive medical surveillance. All had 
been attending the clinic on a regular basis for more than one year.

The patients were assessed by one of us (JR) using three questionnaires: (1) A questionnaire designed to assess the patients' adjustment to living with inflammatory bowel disease and to measure their quality of life. This was finalised after extensive piloting. (2) The Eysenck Personality Inventory ${ }^{5}$ (EPI). (3) The Hospital Anxiety and Depression scale $^{6}$ (HAD).

Only the EPI and HAD scale were administered to the controls. Analysis was carried out on an IBM 3070 computer using The Statistical Package for Social Sciences (SPSS). Disease activity was assessed using Harvey and Bradshaw's simple index of inflammatory bowel disease activity based on symptoms. ${ }^{7}$

\section{Results}

E P I

A numerical value is derived for the personality characteristics of extroversion and neuroticism. Introverted subjects are defined as those scoring below 12 on the extraversion scale of the EPI and neurotic personalities identified as patients scoring over 12 on the neuroticism scale. The points are arbitrarily defined and must be compared with a control population studied under a similar setting. The proportion of patients with the characteristic of high neuroticism in the three groups are shown in Figure 1, together with the confidence intervals of the proportions.

High neuroticism is observed significantly more frequently in patients with inflammatory bowel disease and was seen with equal frequency in patients with established disease as in new referrals. Similarly, a high proportion of patients with inflam-

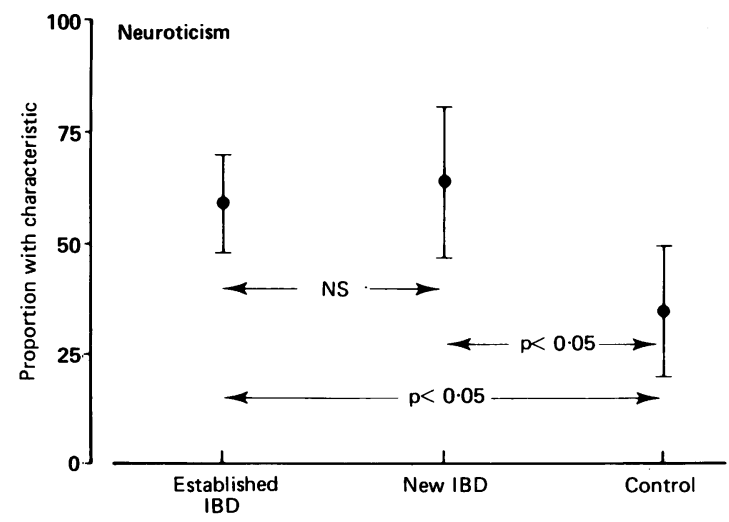

Fig. 1 Proportions of the three groups with high neuroticism scores, together with confidence intervals and the significance levels of the differences observed.

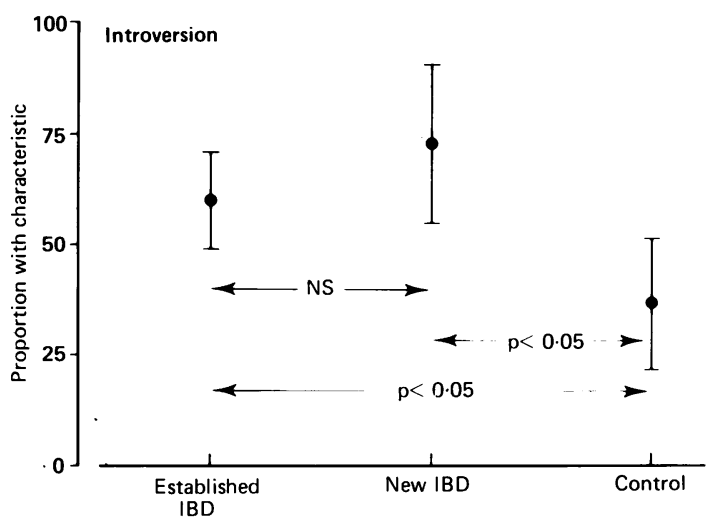

Fig. 2 Proportions of the three groups with low extraversion scores, together with confidence intervals and the significance levels of the differences observed.

matory bowel disease had a low extraversion score compared with controls (Fig. 2). In total, $60 \%$ of IBD patients are identified as introverted or neurotic.

There were small differences in the prevalence of neuroticism and introversion between Crohn's disease and ulcerative colitis: $78 \%$ of Crohn's disease and $54 \%$ of ulcerative colitis patients had high neuroticism scores; $52 \%$ of Crohn's disease and $63 \%$ of ulcerative colitis patients had low extraversion scores (differences not significant).

H A D

A high anxiety, defined as a HAD anxiety score of more than 8 , was less prevalent in the chronic IBD group $(27 \%)$ than in the new IBD $(50 \%)$ and controls (43\%) (Table). Depression, defined as a HAD depression score of more than 8 , was uncommon and

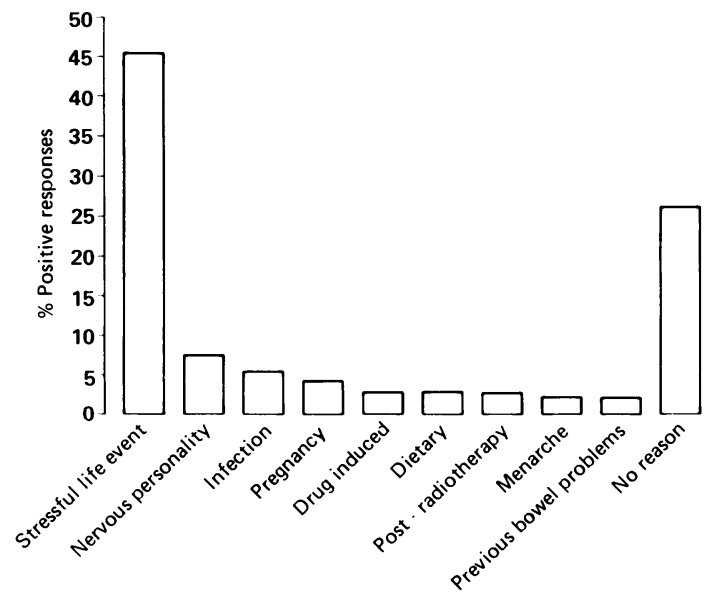

Fig. 3 Factors identified as triggering inflammatory bowel disease in 80 patients with established disease. 
Table Proportions of each group with anxiety and depression

\begin{tabular}{|c|c|c|c|c|c|c|c|c|c|}
\hline & \multicolumn{2}{|c|}{ Established IBD $n=80$} & \multicolumn{2}{|c|}{ New IBD $n=22$} & \multicolumn{2}{|c|}{ Controls $n=40$} & \multicolumn{3}{|c|}{$\begin{array}{l}\text { plevels of differences between } \\
\text {-proportions }\end{array}$} \\
\hline & $\begin{array}{l}\text { Proportion } \\
\text { with } \\
\text { characteristic }\end{array}$ & $\begin{array}{l}95 \% \\
\text { confidence } \\
\text { interval }\end{array}$ & $\begin{array}{l}\text { Proportion } \\
\text { with } \\
\text { characteristic }\end{array}$ & $\begin{array}{l}95 \% \\
\text { confidence } \\
\text { interval }\end{array}$ & $\begin{array}{l}\text { Proportion } \\
\text { with } \\
\text { characteristic }\end{array}$ & $\begin{array}{l}95 \% \\
\text { confidence } \\
\text { interval }\end{array}$ & $\begin{array}{l}\text { Est } \mathrm{v} \\
\text { new }\end{array}$ & $\begin{array}{l}\text { New } \mathrm{v} \\
\text { control }\end{array}$ & $\begin{array}{l}\text { Est } \mathrm{v} \\
\text { control }\end{array}$ \\
\hline Anxiety & 27 & 1737 & 50 & 2971 & 43 & 2858 & NS & NS & NS \\
\hline Depression & 7 & 212 & 18 & 234 & 12 & 222 & NS & NS & NS \\
\hline
\end{tabular}

amongst patients with established IBD occurred only in active disease. Six depressed patients had a mean disease activity index of 14 , compared with 74 patients $(\mathrm{HAD}<8)$ in whom the mean disease activity score was $3(\mathrm{p}<0 \cdot 01)$.

The duration of the disease was not significantly related to neuroticism, anxiety or depression scores but introversion scores increased with the duration of disease $(r=0.51 \mathrm{p}<0.05) 70 \%$ of patients identified a reason why they thought they had developed inflammatory bowel disease. The commonest of these was a stressful life event, identified in 37 patients, and a 'nervous personality' in five. The perceived precipitating factors are tabulated in Figure 3.

\section{Discussion}

This study has shown that the personality traits often observed in patients with inflammatory bowel disease, namely high levels of neuroticism and introversion, are indeed highly prevalent. High anxiety and depression levels were uncommon in the patients studied. These observations are consistent with previously published reports ${ }^{\mathrm{x}}$ and the most important observation in this study is that these traits were present before the diagnosis was established. This might suggest that these personality characteristics are not simply the result of longstanding illness, but are part of the premorbid personality. The patients assessed before the diagnosis was established had not been assessed before the onset of disease, but only before the diagnosis was established, so psychological changes occurring as a result of symptoms before the diagnosis is established are potentially overlooked. The fixing of a diagnostic label is only one component of the illness to which patients respond over time and these start with the earliest perceptions of physiological upset. In Crohn's disease in particular, symptoms may be tolerated for several years before an accurate diagnosis is established. The EPI, being a personality inventory, reflects longstanding personality traits rather than phenomena associated with recent stressful events although this distinction is not absolute.
It is known that psychological factors can have profound effects on a number of demonstrable physiological systems, in particular, gastrointestinal motility ${ }^{9}$ and the immune response ${ }^{10}$ and it is possible that, given a triggering event, such as a gastrointestinal infection, individuals with a particular constitutional predisposition and psychological make up, may develop chronic inflammatory bowel disease.

We have identified two other phenomena which may well be secondary to inflammatory bowel disease, namely, patients tending to become more introverted as the disease progresses and depression occurring only in those patients with persistent disease activity.

Patients with inflammatory disease are aware of an apparent relationship between the disease and psychological stress. Three quarters of them thought they were able to identify a factor which precipitated their illness and by far the commonest factor was a stressful life event.

During the course of this study the interviews were welcomed by the great majority of patients and the whole procedure was thought to be beneficial. A large proportion of patients were unable to discuss their fears with friends and relations and it is not possible for them to do so in a busy gastroenterology outpatient clinic. The opportunity to discuss personal problems in a non-clinical setting appeared to be of value and the patients who were members of the National Association for Crohn's Disease and Colitis found that education and discussion was of great value. Attention to psychological problems can improve the longterm prognosis in IBD. " Work in other areas such as stress after mastectomy has shown the benefit of counselling in coming to terms with disease. ${ }^{12}$ The potential of such an approach with IBD patients is worthy of further study.

\section{References}

1 Murray CD. Psychogenic factors in the actiology of ulcerative colitis and bloody diarrhoea. Am J Med Sci 1930; 180: 239-48.

2 Feldman F, Cantor D, Soll S, Bachrach W. Psychiatric study of a consecutive series of 34 patients with ulcerative colitis. Br Med J 1967; iii: 14-7. 
3 McMahon AW, Schmitt P, Patterson SF, et al. Persenality differences between inflammatory bowel disease patients and their healthy siblings. Psychosom Med 1973; 35: 91-103.

4 Helzer JE, Stillings WA, Chammas S, Norland CC, Alpers DH. A controlled study of the association between ulcerative colitis and psychiatric diagnosis. Dig Dis Sci 1982; 27: 513-8.

5 Eysenck HJ, Eysenck SBG. Manual for the Eysenck personality inventory (EPI). London: University Press, 1964.

6 Zigmond AS, Snaith RP. The hospital anxiety and depression scalc. Acta psychiatr Scand 1983; 67: 361-70.

7 Harvey RF. Bradshaw JM. A simple index of Crohn's disease activity. Lancet 1980 ; i: 514-5.

8 Sheffield BF, Carney MWP. Crohn's Disease: A psychosomatic illness? Br J Psychiatry 1976; 128: 44650 .

9 Almy TP, Tulin M. Alterations in colonic function in man under stress: experimental production of changes simulating irritable colon. Gastroenterology 1947; 8: 616-26.

10 Graham DT, Wolf S, Wolff HG. Changes in tissue sensitivity associated with varying life situations and emotions: their relevance to allergy. J Allergy 1950; 21: 478-86.

11 O'Connor JF. A comprehensive approach to the treatment of ulcerative colitis. In: Hill OW, ed. Modern trends in psychosomatic medicine - 2. London: Butterworths, 1970: 172-88.

12 Cooper CL. Psychosocial stress and cancer. Chichester: J Wiley, 1984. 